\title{
The Comparative Study on Elasticity of Traffic Congestion Delay Cost in Beijing, Shanghai and Guangzhou
}

\author{
Su Zheyi ${ }^{1,1 s t, a, b^{*}}$, Wu Junmin ${ }^{2,2 n d, c}$ \\ ${ }^{1}$ Jiangsu University of Science and Technology Zhenjiang, China \\ ${ }^{2}$ Jiangsu University of Science and Technology Zhenjiang, China
}

\begin{abstract}
This paper proposes the traffic congestion delay cost elasticity concept based on the elastic theory, and analyzes the relationship between traffic congestion delay cost and other influence factors, these factors are: city scale, urban facilities, urban public transport, urban automobile volume, urban road accidents, urban exhaust and urban transportation energy consumption. In this paper, according to the data about Beijing, Shanghai and Guangzhou from 2016 to 2017, the quantitatively study of the elasticity of traffic congestion delay cost was conducted, and the relevant comparison and analysis are made. After that, we put forward countermeasures and suggestions to alleviate urban traffic congestion.
\end{abstract}

\section{INTRODUCTION}

In recent years, we have witnessed great convenience, comfort and safety of people's travel brought by the rapid development of urban traffic. However, with the continuous expansion of urban scale, traffic congestion is becoming increasingly serious ${ }^{[1]}$.Traffic congestion may lead to people' s prolonged delay, resulting in delay cost that cannot be ignored. The more developed the economy means the higher time value and the higher delay cost of traffic congestion. The report of the 19th National Congress of the Communist Party of China clearly put forward that the development strategy of building China into a "transportation power". The Outline of Building a Transportation Power further proposes to build a safe, convenient, efficient, green and economic modern comprehensive transportation system. By 2035, this development goal will be achieved, that is "intelligent, safe, green and shared transportation will be significantly improved, urban traffic congestion will be basically alleviated, and the barrier-free service system will be basically improved"[2]. Therefore, it is of great practical significance to actively study urban traffic congestion, effectively control the delay cost of urban traffic congestion and relieve the pressure brought by urban traffic congestion.

Throughout the contents of traffic congestion cost at home and abroad, we can see that these researches are conducted mainly from the following aspects: the connotation definition ${ }^{[3]}$, evaluation index system construction $^{[4][5]}$ and calculation methods ${ }^{[6][7][8][9][10][11][12]}$. Relevant studies have pointed out that the time cost of traffic congestion is a component of the external cost of traffic congestion, the specific research on it is mainly found in: Schade W, C Doll ,M Maibach et al (2006)'s evaluation about the total benefit of traffic delay cost and congestion charge relative to the reference speed ${ }^{[13]}$; Cui Zhitao and Huo Yamin (2006) focused on the external cost of time loss caused by traffic congestion in a simple conceptual model for calculating the external cost of traffic congestion ${ }^{[14]}$; Luo Qingyu et al. (2007) calculated the extra time cost based on the regional average unit time value ${ }^{[15]}$; Ren hengkuan (2010) calculated and compared the extra time cost of congestion based on questionnaire of travel psychology and the extra time cost of congestion based on wage rate ${ }^{[16]}$; Wu Qibing et al. (2011) established a congestion time cost model from the perspective of residents' travel, and they calculated the extra time cost caused by congestion after combining with the effect coefficient recommended by the World Bank $^{[17]}$; Li Lin (2013) established a new method to estimate the time delay loss of urban road traffic congestion based on road classification, vehicle classification and passenger difference ${ }^{[18]}$; Tong Qiong et al. (2014) evaluated the time delay cost of passengers by taking bus, taxi and private vehicles as the research objects ${ }^{[19]}$; Wang zhenpo et al. (2017) assessed the time delay cost of people with different time values, and proposed that "mobile Internet + transportation" can effectively reduce the time cost of urban residents from the perspective of technological innovation ${ }^{[20]}$; Amap $(2017,2018)$, based on the average monthly wage of each city, calculated the annual congestion time cost per capita from 2016 to 2017 and this cost in Beijing is as high as more than 10000 yuan $^{[21][22]}$; Ren Yiyi (2018) used the estimation method of Texas Transportation Bureau of the United States (Belenky P. $2011^{[23]}$ ) to calculate the extra time cost of typical roads; Chen Zhen (2018), based on passenger time cost and operation cost, built a model for selecting the turn back-station of small routing about urban rail transit ${ }^{[24]}$. Taking macro data as samples, and time cost as a part of social cost of traffic congestion,

\footnotetext{
a18902256742@163.com

b*Corresponding author: Su Zheyi, 18902256742@163.com

cwujunmin824@163.com
} 
most of the relevant studies conduct their discussions and assessments, but they haven' $t$ involved themselves in the elasticity research on delay of traffic congestion.

Based on the elastic theory, it is rare to see the study on the influene factors about the elasticity of traffic congestion delay cost. The 13th Five-year Plan for Economic and Social Development of the People' $s$ Republic of China clearly proposes to optimize the hub spatial layout and build international comprehensive transportation hubs in such cities as Beijing, Shanghai and Guangzhou ${ }^{[26]}$, which are the research objects of this paper. Therefore, as the top three of China' s top 100 cities in 2016-2017, these three representative megacities have more than 10 million permanent residents, and they also rank in the top 11 in the annual congestion list. Taking the delay cost as the observation point of traffic congestion, the relevant factors affecting the delay cost of traffic congestion are analyzed, and it is caculated through elastic formula. Meanwhile, this paper also analyzes and compares the elasticity degree of the impact on the delay cost of traffic congestion of the relevant factors in each city, and finds out the main, secondary and general influence factors, so as to provide policy warraty for the government to plan urban traffic facilities and alleviate urban traffic congestion.

\section{Delay Cost of Traffic Congestion and ITS INFLUENCING FACTORS}

Traffic congestion is the result caused by the fact that the traffic demand greatly exceeds the traffic capacity created by traffic facilities, which can not be relieved in time. Traffic congestion carries obvious temporal and spatial characteristics, and it does not appear at any time of the day or any place ${ }^{[18]}$. It is related to people' $s$ travelling time and the spatial structure of traffic network, and mainly occurs at busy intersections during rush hours ${ }^{[27]}$. The "annual traffic analysis report of major cities in China", released by Amap, uses "congestion delay index" as the evaluation index of urban congestion degree. The congestion delay index refers to the ratio of the average actual travel time of urban residents to the travel time under free flow state, that is, congestion delay index $=$ travel time $/$ free flow (unimpeded) travel time. From the perspective of traffic travelers, this index expresses the time cost of traffic congestion in a simple and understandable way ${ }^{[21][22]}$. More congested traffic means higher congestion delay index and higher delay cost. Therefore, the congestion delay index can be used to quantify the delay cost of traffic congestion. In this paper, the whole day delay index of urban congestion is used to quantify the delay cost of urban traffic congestion.

The fundamental reason of traffic congestion in China' $\mathrm{s}$ big cities lies in the imbalance of urban functional layout leads to the abnormal spatial and temporal distribution of traffic demand. Urban space expansion and structural adjustment are persued at the cost of ignoring synchronous optimization and adjustment of urban functional layout, which is characterized by unbalanced distribution of population and employment, unbalanced allocation of public service resources, imperfect traffic planning and design, the missing management system for normalized traffic demand, imbalance of traffic structure and insufficient management of intelligent and systematic traffic ${ }^{[28]}$. The systematization and complexity of traffic congestion in megalopolis need to be studied from multiple perspectives. From the perspective of traffic congestion delay cost, this paper analyzes the influencing factors of traffic congestion delay cost (see Table 1 for details) through the main statistical indicators (city scale, urban facilities, urban public transport, urban motor vehicle ownership, urban road accidents, urban exhaust, urban transportation energy consumption, etc.) in the statistical yearbook, so the analyses to some extent can be scientific and objective.

Table 1 Influencing Factors of Traffic Congestion Delay Cost

\begin{tabular}{|c|c|c|}
\hline \multirow{5}{*}{$\begin{array}{l}C: \text { Delay } \\
\text { cost of traffic } \\
\text { congestion }\end{array}$} & $x_{1}:$ City scale & $\begin{array}{l}\left.x_{11} \text { Population density (people } / \mathrm{km}^{2}\right) ; x_{12} \text { Density of the employed at the end of the } \\
\left.\text { year (person } / \mathrm{m}^{2}\right) ; x_{13} \text { Density of children in kindergarten (people } / \mathrm{km}^{2} \text { ) }\end{array}$ \\
\hline & $\begin{array}{l}x_{2}: \text { Urban } \\
\text { facilities }\end{array}$ & $\begin{array}{l}x_{21} \text { Per capita urban road area }\left(\mathrm{km}^{2} / \text { person); } x_{22} \text { Per capita urban road and }\right. \\
\text { Bridge (set / } 10000 \text { people); } x_{23} \text { Per capita urban road lighting (lamp / } 10000 \\
\text { people); } x_{24} \text { Public transport vehicles (buses, trams, rail transit) per } 10000 \text { people }\end{array}$ \\
\hline & $\begin{array}{l}x_{3}: \text { Urban public } \\
\quad \text { transport }\end{array}$ & $\begin{array}{l}x_{31} \text { Electric vehicle operating length / km; } x_{32} \text { operation of lectric vehicle / unit; } \\
x_{33} \text { Electric vehicle passenger volume / } 10000 \text { person time; } x_{34} \text { Rail operation } \\
\text { vehicle / unit; } x_{35} \text { Rail passenger traffic volume / } 10000 \text { person time; } x_{36} \text { Taxi } \\
\text { (unit / } 10000 \text { person time) per } 10000 \text { people; } x_{37} \text { Passenger volume and number of } \\
\text { trips ( } 10000 \text { person times) }\end{array}$ \\
\hline & $\begin{array}{r}x_{4}: \text { Urban motor } \\
\text { vehicle ownership }\end{array}$ & $\begin{array}{l}x_{41} \text { Private (personal) cars (unit } / 10000 \text { people) owned by every ten thousand } \\
\text { people; } x_{42} \text { civil vehicles (unit / } 10000 \text { people) owned by every ten thousand } \\
\text { people; } x_{43} \text { civil trucks (unit / } 10000 \text { people) owned by every ten thousand } \\
\text { people; } x_{44} \text { civil passenger vehicles (unit } / 10000 \text { people) owned by every ten } \\
\text { thousand people }\end{array}$ \\
\hline & $\begin{array}{l}x_{5}: \text { Urban road } \\
\text { accidents }\end{array}$ & $x_{51}$ Occurrence times(cases, pieces); $x_{52}$ direct property loss (10000 yuan) \\
\hline
\end{tabular}




\begin{tabular}{l|l|l}
\hline & $x_{6}:$ Urban exhaust & $x_{61}$ Days of air quality reaching or better than grade II \\
\cline { 2 - 3 } & $\begin{array}{c}x_{7}: \text { Urban } \\
\text { transportation } \\
\text { energy } \\
\text { consumption }\end{array}$ & $\begin{array}{c}x_{71} \text { Terminal energy consumption (including warehouse post) (10000 tons of } \\
\text { standard coal) }\end{array}$ \\
\hline
\end{tabular}

\section{ELASTIC FORMULA OF TRAFFIC Congestion DELAY COST}

The elasticity of traffic congestion delay cost refers to the comparison of the change ratio between the two variables: the delay cost of traffic congestion and its influencing factors, that is, the comparison of the change rates between the influencing factors of traffic congestion delay cost and traffic congestion delay cost. Traffic congestion delay cost elasticity is expressed by $E_{d}$, so $E_{d}=\frac{\Delta C / C}{\Delta x / x}=\frac{\Delta C}{\Delta x} \cdot \frac{x}{C}, x$ represents the influencing factors of the delay cost of traffic congestion, $C$ represents the delay cost of traffic congestion, elasticity $E_{d}$ reflects the degree of change in congestion delay cost caused by the change of influencing factors of traffic congestion delay cost, or the response of traffic congestion delay cost to the change of its influencing factors. When the factors affect the delay cost of traffic congestion, showing $x_{1} \rightarrow x_{2}$ and $x_{2} \rightarrow x_{1}$, the elastic calculation results will generally be different. In order to avoid this situation, the midpoint method is adopted in this paper, and the formula is $E_{d}=\frac{\Delta C /\left(C_{1}+C_{2}\right) / 2}{\Delta x /\left(x_{1}+x_{2}\right) / 2}=\frac{\Delta C}{\Delta x} \cdot \frac{x_{1}+x_{2}}{C_{1}+C_{2}}$.

There are three kinds of delay cost elasticity of traffic congestion: When $E_{d}>1$, the change rate of delay cost of traffic congestion is faster than that of its influencing factors. That is to say, the delay cost of traffic congestion reacts strongly to the change of its influencing factors, which is called full elasticity; when $E_{d}=1$, the change rates between the delay cost of traffic congestion and its

\begin{tabular}{|c|c|c|c|c|c|c|c|}
\hline \multirow{3}{*}{\multicolumn{2}{|c|}{ Influence Factors }} & \multicolumn{2}{|c|}{ Beijing } & \multicolumn{2}{|c|}{ Shanghai } & \multicolumn{2}{|c|}{ Guangzhou } \\
\hline & & \multirow{2}{*}{$\begin{array}{c}C \\
1.73 \rightarrow 1.692\end{array}$} & \multirow{2}{*}{ Elasticity } & \multirow{2}{*}{$\frac{C}{1.59 \rightarrow 1.58}$} & \multirow{2}{*}{ Elasticity } & \multirow{2}{*}{$\begin{array}{c}C \\
1.65 \rightarrow 1.674\end{array}$} & \multirow{2}{*}{ Elasticity } \\
\hline & & & & & & & \\
\hline \multirow{3}{*}{$x_{1}$} & $x_{11}$ & $1324 \rightarrow 1323$ & 29.39 & $3816 \rightarrow 3814$ & 12.03 & $1889 \rightarrow 1950$ & 0.45 \\
\hline & $x_{12}$ & $743 \rightarrow 760$ & -0.98 & $2153 \rightarrow 2165$ & -1.14 & $1124 \rightarrow 1160$ & 0.46 \\
\hline & $x_{13}$ & $25 \rightarrow 27$ & -0.29 & $88 \rightarrow 90$ & -0.28 & $62 \rightarrow 65$ & 0.31 \\
\hline \multirow{4}{*}{$x_{2}$} & $x_{21}$ & $4.73 \rightarrow 4.77$ & -2.64 & $12.09 \rightarrow 12.34$ & -0.31 & $8.64 \rightarrow 10.98$ & 0.06 \\
\hline & $x_{22}$ & $0.96 \rightarrow 1.05$ & -0.25 & $1.07 \rightarrow 1.11$ & -0.17 & $1.01 \rightarrow 1.03$ & 0.74 \\
\hline & $x_{23}$ & $138.34 \rightarrow 108.77$ & 0.09 & $231.06 \rightarrow 239.46$ & -0.18 & $237.78 \rightarrow 231.69$ & -0.56 \\
\hline & $x_{24}$ & $12.84 \rightarrow 14.26$ & -0.21 & $12.70 \rightarrow 13.94$ & -0.07 & $11.51 \rightarrow 11.71$ & 0.84 \\
\hline \multirow{2}{*}{$x_{3}$} & $x_{31}$ & $19818 \rightarrow 19290$ & 0.82 & $24169 \rightarrow 24161$ & 19.06 & $20795 \rightarrow 17433$ & -0.08 \\
\hline & $x_{32}$ & $22688 \rightarrow 25624$ & -0.18 & $16693 \rightarrow 17461$ & -0.14 & $14074 \rightarrow 14852$ & 0.27 \\
\hline
\end{tabular}

influencing factors are equal. That is, the delay cost of traffic congestion and its influencing factors change in the same range, which is called single elasticity; when $E_{d}<1$, the change rate of traffic congestion delay cost is less than that of its influencing factors. That is, the change of traffic congestion delay cost reacts moderately to the change of its influencing factors, which is called inelasticity. There are two special cases of traffic congestion delay cost elasticity: When $E_{d}=0$, the delay cost of traffic congestion is a constant, and the delay cost of traffic congestion does not change with its influencing factors, which is called complete inelasticity; when $E_{d} \rightarrow \infty$, if the factors affecting the delay cost of traffic congestion remain unchanged, the delay cost of traffic congestion iwill be infinite, which is called infinite elasticity.

The comprehensive elasticity of traffic congestion delay cost refers to the elastic algebraic sum of influencing factors considered in traffic congestion delay cost, which is expressed by the following formula:

$$
E=\sum_{i=1}^{n} E_{d i}=E_{d 1}+E_{d 2}+E_{d 3}+\cdots \cdots+E_{d n}
$$

\section{Elastic Calculation of traffic Congestion Delay Cost in BeiJing, SHANGHAI AND GUANGZHOU}

According to table 1 and the elastic formula of traffic congestion delay cost, the elasticity of traffic congestion delay in Beijing, Shanghai and Guangzhou from 2016 to 2017 is calculated, as shown in Table 2. 


\begin{tabular}{|c|c|c|c|c|c|c|c|}
\hline & $x_{33}$ & $369019 \rightarrow 335595$ & 0.23 & $239112 \rightarrow 220272$ & 0.08 & $241358 \rightarrow 238503$ & -1.21 \\
\hline & $x_{34}$ & $5204 \rightarrow 5342$ & -0.85 & $4025 \rightarrow 4753$ & -0.04 & $2048 \rightarrow 2408$ & 0.09 \\
\hline & $x_{35}$ & $365934 \rightarrow 377801$ & -0.70 & $340106 \rightarrow 353769$ & -0.16 & $257119 \rightarrow 280561$ & 0.17 \\
\hline & $x_{36}$ & $31.52 \rightarrow 31.55$ & -23.35 & $19.54 \rightarrow 19.55$ & -12.33 & $15.74 \rightarrow 15.37$ & -0.61 \\
\hline & $x_{37}$ & $47665 \rightarrow 39378$ & 0.12 & $47911 \rightarrow 42173$ & 0.05 & $56421 \rightarrow 60676$ & 0.20 \\
\hline \multirow{4}{*}{$x_{4}$} & $x_{41}$ & $2083.85 \rightarrow 2152.30$ & -0.69 & $\begin{array}{c}1003.06 \rightarrow 1134.7 \\
1\end{array}$ & -0.05 & $1316.60 \rightarrow 1319.19$ & 7.35 \\
\hline & $x_{42}$ & $2523.82 \rightarrow 2597.32$ & -0.77 & $\begin{array}{c}1334.63 \rightarrow 1492.8 \\
5\end{array}$ & -0.06 & $1638.06 \rightarrow 1654.77$ & 1.42 \\
\hline & $x_{43}$ & $151.87 \rightarrow 169.07$ & -0.21 & $90.34 \rightarrow 127.40$ & -0.02 & $208.08 \rightarrow 219.27$ & 0.28 \\
\hline & $x_{44}$ & $2344.33 \rightarrow 2399.23$ & -0.96 & $\begin{array}{c}1214.41 \rightarrow 1357.0 \\
1\end{array}$ & -0.06 & $1422.32 \rightarrow 1427.55$ & 3.93 \\
\hline \multirow{2}{*}{$x_{5}$} & $x_{51}$ & $3163 \rightarrow 3223$ & -1.18 & $795 \rightarrow 709$ & 0.06 & $2544 \rightarrow 2336$ & -0.17 \\
\hline & $x_{52}$ & $2819.4 \rightarrow 3149.5$ & -0.20 & $370.8 \rightarrow 362.8$ & 0.29 & $938 \rightarrow 969$ & 0.44 \\
\hline$x_{6}$ & $x_{61}$ & $198 \rightarrow 226$ & -0.17 & $276 \rightarrow 275$ & 1.74 & $310 \rightarrow 294$ & -0.27 \\
\hline$x_{7}$ & $x_{71}$ & $1136.84 \rightarrow 1201.28$ & -0.40 & $\begin{array}{c}2356.93 \rightarrow 2571.1 \\
8\end{array}$ & -0.07 & $1280.60 \rightarrow 1378.24$ & 0.20 \\
\hline
\end{tabular}
dic report of public transport big data analytics about major cities in China from 2016 to 2017, these two reports provided by Amap; China Statistical Yearbook in 2016-2018, Beijing Statistical Yearbook in 2016-2018, Shanghai Statistical Yearbook in 2016-2018, GuangzhouStatistical Yearbook in 2016-2018, and China energy statistical yearbook2016 2018; according to part of the data, the "final energy consumption in Beijing" is obtained by subtracting "total energy consumption of Beijing transportation, storage and postal service" (2016-2017, $1249.4,1312.69,1386.78)$ and "loss of transportation and transmission and distribution" (2016-2017, 171.13, $175.85,185.50)$

\section{Comparative Study on the Elasticity OF TRAFFIC CONGESTION DELAY COST IN BeiJing, Shanghal AND Guangzhou}

\subsection{Comprehensive Elasticity of Traffic Congestion Delay Cost}

According to the comprehensive elastic formula of traffic congestion delay cost and relevant data in Table 2, the following conclusions are obtained:

Table 3 The elastic extent, change direction and type of various influencing factors of traffic congestion delay cost in Beijing, Shanghai and Guangzhou in 2016-2017

\begin{tabular}{|c|c|c|c|c|c|c|c|c|c|c|}
\hline \multirow{3}{*}{$\begin{array}{c}\text { Influe } \\
\text { ncing } \\
\text { Factor } \\
\text { s }\end{array}$} & \multicolumn{9}{|c|}{ Elasticity Analysis } & \multirow{3}{*}{$\begin{array}{c}\text { Influence } \\
\text { Degree }\end{array}$} \\
\hline & \multicolumn{3}{|c|}{ Beijing } & \multicolumn{3}{|c|}{ Shanghai } & \multicolumn{3}{|c|}{ Guangzhou } & \\
\hline & Extent & Direction & Type & Extent & Direction & Type & Extent & Direction & Type & \\
\hline$x_{11}$ & 29.39 & same & full & 12.03 & same & full & 0.45 & same & $\begin{array}{c}\text { inelasticit } \\
y\end{array}$ & $\mathrm{~B}>\mathrm{S}>\mathrm{G}$ \\
\hline$x_{12}$ & 0.98 & opposite & $\begin{array}{c}\text { inelasticit } \\
\mathrm{y}\end{array}$ & 1. 14 & opposite & full & 0.46 & same & $\begin{array}{c}\text { inelasticit } \\
y\end{array}$ & $\mathrm{~S}>\mathrm{B}>\mathrm{G}$ \\
\hline$x_{13}$ & 0.29 & opposite & $\begin{array}{c}\text { inelasticit } \\
\mathrm{y}\end{array}$ & 0.28 & opposite & $\begin{array}{c}\text { inelasticit } \\
\mathrm{y}\end{array}$ & 0.31 & same & $\begin{array}{c}\text { inelasticit } \\
\mathrm{y}\end{array}$ & $\mathrm{G}>\mathrm{B}>\mathrm{S}$ \\
\hline
\end{tabular}

\subsection{Elastic Analysis of Influencing Factors of Traffic Congestion Delay Cost}

According to the relevant data in Table 2, the elastic extent, change direction and type of various influencing factors of traffic congestion delay cost in Beijing, Shanghai and Guangzhou from 2016 to 2017 are obtained, as shown in Table 3. 


\begin{tabular}{|c|c|c|c|c|c|c|c|c|c|c|}
\hline$x_{21}$ & 2.64 & opposite & full & 0.31 & opposite & $\begin{array}{c}\text { inelasticit } \\
\mathrm{y}\end{array}$ & 0.06 & same & $\begin{array}{c}\text { inelasticit } \\
\mathrm{y}\end{array}$ & $\mathrm{B}>\mathrm{S}>\mathrm{G}$ \\
\hline$x_{22}$ & 0.25 & opposite & $\begin{array}{c}\text { inelasticit } \\
\mathrm{y}\end{array}$ & 0.17 & opposite & $\begin{array}{c}\text { inelasticit } \\
\mathrm{y}\end{array}$ & 0.74 & same & $\begin{array}{c}\text { inelasticit } \\
\mathrm{y}\end{array}$ & $\mathrm{G}>\mathrm{B}>\mathrm{S}$ \\
\hline$x_{23}$ & 0.09 & same & $\begin{array}{c}\text { inelasticit } \\
\mathrm{y}\end{array}$ & 0.18 & opposite & $\begin{array}{c}\text { inelasticit } \\
\mathrm{y}\end{array}$ & 0.56 & opposite & $\begin{array}{c}\text { inelasticit } \\
\mathrm{y}\end{array}$ & $\mathrm{G}>\mathrm{S}>\mathrm{B}$ \\
\hline$x_{24}$ & 0.21 & opposite & $\begin{array}{c}\text { inelasticit } \\
\mathrm{y}\end{array}$ & 0.07 & opposite & $\begin{array}{c}\text { inelasticit } \\
\mathrm{y}\end{array}$ & 0.84 & same & $\begin{array}{c}\text { inelasticit } \\
\mathrm{y}\end{array}$ & $\mathrm{G}>\mathrm{B}>\mathrm{S}$ \\
\hline$x_{31}$ & 0.82 & same & $\begin{array}{c}\text { inelasticit } \\
\mathrm{y}\end{array}$ & 19. 06 & same & full & 0.08 & opposite & $\begin{array}{c}\text { inelasticit } \\
y\end{array}$ & $\mathrm{~S}>\mathrm{B}>\mathrm{G}$ \\
\hline$x_{32}$ & 0.18 & opposite & $\begin{array}{c}\text { inelasticit } \\
\mathrm{y}\end{array}$ & 0.14 & opposite & $\begin{array}{c}\text { inelasticit } \\
\mathrm{y}\end{array}$ & 0.27 & same & $\begin{array}{c}\text { inelasticit } \\
\mathrm{y}\end{array}$ & $\mathrm{G}>\mathrm{B}>\mathrm{S}$ \\
\hline$x_{33}$ & 0.23 & same & $\begin{array}{c}\text { inelasticit } \\
\mathrm{y}\end{array}$ & 0.08 & same & $\begin{array}{c}\text { inelasticit } \\
\mathrm{y}\end{array}$ & 1.21 & opposite & full & $\mathrm{G}>\mathrm{B}>\mathrm{S}$ \\
\hline$x_{34}$ & 0.85 & opposite & $\begin{array}{c}\text { inelasticit } \\
\mathrm{y}\end{array}$ & 0.04 & opposite & $\begin{array}{c}\text { inelasticit } \\
\mathrm{y}\end{array}$ & 0.09 & same & $\begin{array}{c}\text { inelasticit } \\
\mathrm{y}\end{array}$ & $\mathrm{B}>\mathrm{G}>\mathrm{S}$ \\
\hline$x_{35}$ & 0.70 & opposite & $\begin{array}{c}\text { inelasticit } \\
\mathrm{y}\end{array}$ & 0.16 & opposite & $\begin{array}{c}\text { inelasticit } \\
\mathrm{y}\end{array}$ & 0.17 & same & $\begin{array}{c}\text { inelasticit } \\
\mathrm{y}\end{array}$ & $\mathrm{B}>\mathrm{G}>\mathrm{S}$ \\
\hline$x_{36}$ & 23. 35 & opposite & full & 12.33 & opposite & full & 0.61 & opposite & $\begin{array}{c}\text { inelasticit } \\
\mathrm{y}\end{array}$ & $\mathrm{B}>\mathrm{S}>\mathrm{G}$ \\
\hline$x_{37}$ & 0.12 & same & $\begin{array}{c}\text { inelasticit } \\
\mathrm{y}\end{array}$ & 0.05 & same & $\begin{array}{c}\text { inelasticit } \\
\mathrm{y}\end{array}$ & 0.20 & same & $\begin{array}{c}\text { inelasticit } \\
\mathrm{y}\end{array}$ & $\mathrm{G}>\mathrm{B}>\mathrm{S}$ \\
\hline$x_{41}$ & 0.69 & opposite & $\begin{array}{c}\text { inelasticit } \\
\mathrm{y}\end{array}$ & 0.05 & opposite & $\begin{array}{c}\text { inelasticit } \\
\mathrm{y}\end{array}$ & 7. 35 & same & full & $\mathrm{G}>\mathrm{B}>\mathrm{S}$ \\
\hline$x_{42}$ & 0.77 & opposite & $\begin{array}{c}\text { inelasticit } \\
\mathrm{y}\end{array}$ & 0.06 & opposite & $\begin{array}{c}\text { inelasticit } \\
\mathrm{y}\end{array}$ & 1. 42 & same & full & $\mathrm{G}>\mathrm{B}>\mathrm{S}$ \\
\hline$x_{43}$ & 0.21 & opposite & $\begin{array}{c}\text { inelasticit } \\
\mathrm{y}\end{array}$ & 0.02 & opposite & $\begin{array}{c}\text { inelasticit } \\
\mathrm{y}\end{array}$ & 0.28 & same & $\begin{array}{c}\text { inelasticit } \\
\mathrm{y}\end{array}$ & $\mathrm{G}>\mathrm{B}>\mathrm{S}$ \\
\hline$x_{44}$ & 0.96 & opposite & $\begin{array}{c}\text { inelasticit } \\
\mathrm{y}\end{array}$ & 0.06 & opposite & $\begin{array}{c}\text { inelasticit } \\
\mathrm{y}\end{array}$ & 3.93 & same & full & $\mathrm{G}>\mathrm{B}>\mathrm{S}$ \\
\hline$x_{51}$ & 1. 18 & opposite & full & 0.06 & same & $\begin{array}{c}\text { inelasticit } \\
\mathrm{y}\end{array}$ & 0.17 & opposite & $\begin{array}{c}\text { inelasticit } \\
\mathrm{y}\end{array}$ & $\mathrm{B}>\mathrm{G}>\mathrm{S}$ \\
\hline$x_{52}$ & 0.20 & opposite & $\begin{array}{c}\text { inelasticit } \\
\mathrm{y}\end{array}$ & 0.29 & same & $\begin{array}{c}\text { inelasticit } \\
\mathrm{y}\end{array}$ & 0.44 & same & $\begin{array}{c}\text { inelasticit } \\
\mathrm{y}\end{array}$ & $\mathrm{G}>\mathrm{S}>\mathrm{B}$ \\
\hline$x_{61}$ & 0.17 & opposite & $\begin{array}{c}\text { inelasticit } \\
\mathrm{y}\end{array}$ & 1.74 & same & full & 0.27 & opposite & $\begin{array}{c}\text { inelasticit } \\
\mathrm{y}\end{array}$ & $\mathrm{S}>\mathrm{G}>\mathrm{B}$ \\
\hline$x_{71}$ & 0.40 & opposite & $\begin{array}{c}\text { inelasticit } \\
\mathrm{y}\end{array}$ & 0.07 & opposite & $\begin{array}{c}\text { inelasticit } \\
\mathrm{y}\end{array}$ & 0.20 & same & $\begin{array}{c}\text { inelasticit } \\
\mathrm{y}\end{array}$ & $\mathrm{B}>\mathrm{G}>\mathrm{S}$ \\
\hline
\end{tabular}

\subsection{Horizontal Comparison of Elasticity of Traffic Congestion Delay Cost}

Firstly, influencing factors make a difference from the same direction. The factors influencing the delay cost of traffic congestion of Beijing, Shanghai and Guangzhou in the same direction are as follows: $x_{11}$ represents population density and $x_{37}$ represents passenger volume and number of trips of taxi and cars. The degree of their influence is different: When the population density increases by $1 \%$, the delay cost of traffic congestion in Beijing, Shanghai and Guangzhou will increase by $29.39 \%, 12.03 \%$ and $0.45 \%$ respectively, the influence degree from the same direction from big to small is Beijing, Shanghai, Guangzhou; when the passenger volume and number of trips of taxi and cars increase by $1 \%$, the delay cost of traffic congestion in Beijing, Shanghai and Guangzhou will increase by $0.12 \%, 0.05 \%$, $0.20 \%$ respectively, the influence degree from the same direction from big to small is Guangzhou, Beijing and Shanghai.

Secondly, influencing factors play parts from the opposite direction. These factors influencing the delay cost of traffic congestion in Beijing, Shanghai and Guangzhou are as follows: $x_{36}$ represents taxis owned by every ten thousand people. The impact is different: If every $1 \%$ increase in taxi ownership per 10000 people, the delay cost of traffic congestion in Beijing, Shanghai and Guangzhou will be reduced by $23.35 \%, 12.33 \%$ and $0.61 \%$ respectively, and the degree of opposite impact from big to small is Beijing, Shanghai and Guangzhou.

Thirdly, uncertainty of direction. The differences in cities make the elasticity appear in the same or opposite direction, so the influence brought by other factors of delay cost of traffic congestion in Beijing, Shanghai and Guangzhou are different, as shown in Table 3.

\subsection{Longitudinal Comparison of Elasticity of Traffic Congestion Delay Cost}

When elasticity of traffic congestion delay cost $E_{d} \geq 1$, it is called the main factor affecting the delay cost of traffic congestion; When elasticity of traffic congestion delay cost $0.5 \leq E_{d}<1$, it is called the secondary factor affecting the delay cost of traffic congestion; When elasticity of traffic congestion delay cost $0 \leq E_{d}<0.5$, it is called the general factor affecting the delay cost of traffic congestion. The main, secondary factors and general factors affecting the delay cost of traffic congestion in Beijing, Shanghai and Guangzhou are different, as shown in Table 4. 
Table 4 The main, secondary factors and general factors affecting the delay cost of traffic congestion in Beijing, Shanghai and Guangzhou

\begin{tabular}{|c|c|c|c|c|}
\hline \multicolumn{2}{|c|}{$\begin{array}{c}\text { Influencing } \\
\text { Factors }\end{array}$} & \multirow{2}{*}{$\begin{array}{c}\text { Beijing } \\
\text { main factor }\end{array}$} & \multirow{2}{*}{$\begin{array}{l}\text { Shanghai } \\
\text { main factor }\end{array}$} & \multirow{2}{*}{$\begin{array}{l}\text { Guangzhou } \\
\text { general factor }\end{array}$} \\
\hline \multirow{3}{*}{$x_{1}$} & $x_{11}$ & & & \\
\hline & $x_{12}$ & secondary factor & main factor & general factor \\
\hline & $x_{13}$ & general factor & general factor & general factor \\
\hline \multirow{4}{*}{$x_{2}$} & $x_{21}$ & main factor & general factor & general factor \\
\hline & $x_{22}$ & general factor & general factor & secondary factor \\
\hline & $x_{23}$ & general factor & general factor & secondary factor \\
\hline & $x_{24}$ & general factor & general factor & secondary factor \\
\hline \multirow{7}{*}{$x_{3}$} & $x_{31}$ & secondary factor & main factor & general factor \\
\hline & $x_{32}$ & general factor & general factor & general factor \\
\hline & $x_{33}$ & general factor & general factor & main factor \\
\hline & $x_{34}$ & secondary factor & general factor & general factor \\
\hline & $x_{35}$ & secondary factor & general factor & general factor \\
\hline & $x_{36}$ & main factor & main factor & secondary factor \\
\hline & $x_{37}$ & general factor & general factor & general factor \\
\hline \multirow{4}{*}{$x_{4}$} & $x_{41}$ & secondary factor & general factor & main factor \\
\hline & $x_{42}$ & secondary factor & general factor & main factor \\
\hline & $x_{43}$ & general factor & general factor & general factor \\
\hline & $x_{44}$ & secondary factor & general factor & main factor \\
\hline \multirow{2}{*}{$x_{5}$} & $x_{51}$ & main factor & general factor & general factor \\
\hline & $x_{52}$ & general factor & general factor & general factor \\
\hline$x_{6}$ & $x_{61}$ & general factor & main factor & general factor \\
\hline$x_{7}$ & $x_{71}$ & general factor & general factor & general factor \\
\hline
\end{tabular}

From table 4, we can find that:

Firstly, longitudinal comparison of the elasticity of traffic congestion delay cost in Beijing. According to the elasticity of traffic congestion delay cost in Beijing, the following factors affecting the delay cost of traffic congestion in Beijing are the main factors: Population density $x_{11}$, per capita urban road area $x_{21}$, taxi owned by per 10000 people $x_{36}$, occurance times of urban road accidents $x_{51}$, the degree of influence is $x_{11}>x_{36}>x_{21}>x_{51}$. When the main factors increase by $1 \%$, the delay cost of traffic congestion will increase by $29.39 \%$, decrease by $23.35 \%, 2.64 \%$ and $1.18 \%$ respectively. The following factors affecting the delay cost of traffic congestion in Beijing are the secondary factors: Density of the employed at the end of the year $x_{12}$, electric vehicle operating length $x_{31}$, rail operation vehicle $x_{34}$, rail passenger traffic volume $x_{35}$, private cars owned by every ten thousand people $x_{41}$, civil vehicles owned by every ten thousand people $x_{42}$, civil passenger vehicles owned by every ten thousand people $x_{44}$. Every $1 \%$ increase in secondary factors means that the delay cost of traffic congestion will be decreased by $0.98 \%$, increased by $0.82 \%$, and decreased by $0.85 \%, 0.70 \%$, $0.69 \%, 0.77 \%$ and $0.96 \%$ respectively. The following factors affecting the delay cost of traffic congestion in
Beijing are the general factors: Density of children in kindergarten $x_{13}$, per capita urban road and bridge $x_{22}$, per capita urban road lighting $x_{23}$, public transport vehicles per 10000 people $x_{24}$, operation of electric vehicle $x_{32}$, electric vehicle passenger volume $x_{33}$, passenger volume and number of trips $x_{37}$, civil trucks owned by every ten thousand people $x_{43}$, direct property loss caused by urban road accidents $x_{52}$, urban exhaust $x_{61}$, energy consumption of urban transportation $x_{71}$. When the general factors increase by every $1 \%$, the delay cost of traffic congestion in Beijing only increases (in the same direction) or decreases (in the opposite direction) by less than $0.5 \%$.

Secondly, longitudinal comparison of the elasticity of traffic congestion delay cost in Shanghai. According to the elasticity of traffic congestion delay cost in Shanghai, the following factors affecting the delay cost of traffic congestion in Shanghai are the main factors: Population density $x_{11}$, density of the employed at the end of the year $x_{12}$, electric vehicle operating length $x_{31}$, taxi owned by per 10000 people $x_{36}$, urban exhaust $x_{61}$, the degree of influence is $x_{31}>x_{36}>x_{11}>x_{61}>x_{12}$. When the main factors increase by $1 \%$, the delay cost of traffic congestion will increase by $19.06 \%$, decrease by $12.33 \%$, increase by 
$12.03 \%$ and $1.74 \%$, and decrease by $1.14 \%$. There is no secondary factor affecting the delay cost of traffic congestion. The following factors affecting the delay cost of traffic congestion in Shanghai are the general factors: Density of children in kindergarten $x_{13}$, per capita urban road area $x_{21}$, per capita urban road and bridge $x_{22}$, per capita urban road lighting $x_{23}$, public transport vehicles per 10000 people $x_{24}$, operation of electric vehicle $x_{32}$, electric vehicle passenger volume $x_{33}$, rail operation vehicle $x_{34}$, rail passenger traffic volume $x_{35}$, passenger volume and number of trips $x_{37}$, private cars owned by every ten thousand people $x_{41}$, civil vehicles owned by every ten thousand people $x_{42}$, civil trucks owned by every ten thousand people $x_{43}$, civil passenger vehicles owned by every ten thousand people $x_{44}$, occurance times of urban road accidents $x_{51}$, direct property loss caused by urban road accidents $x_{52}$, energy consumption of urban transportation $x_{71}$. When the general factors increase by every $1 \%$, the delay cost of traffic congestion in Shanghai only increases (in the same direction) or decreases (in the opposite direction) by less than $0.5 \%$.

Thirdly, longitudinal comparison of the elasticity of traffic congestion delay cost in Guangzhou. According to the elasticity of traffic congestion delay cost in Guangzhou, the following factors affecting the delay cost of traffic congestion in Guangzhou are the main factors: electric vehicle passenger volume $x_{33}$, private cars owned by every ten thousand people $x_{41}$, civil vehicles owned by every ten thousand people $x_{42}$, civil passenger vehicles owned by every ten thousand people $x_{44}$, the degree of influence is $x_{41}>x_{44}>x_{42}>x_{33}$. When the main factors increase by $1 \%$, the delay cost of traffic congestion will increase by $7.35 \%, 3.93 \%, 1.42 \%$ and decrease by $1.21 \%$. The following factors affecting the delay cost of traffic congestion in Guangzhou are the secondary factors: Per capita urban road and bridge $x_{22}$, per capita urban road lighting $x_{23}$, public transport vehicles per 10000 people $x_{24}$, taxi owned by per 10000 people $x_{36}$. When the secondary factors increase by $1 \%$, the delay cost of traffic congestion will increase by $0.74 \%$, decrease by $0.56 \%$, increase by $0.84 \%$ and decrease by $0.61 \%$. The following factors affecting the delay cost of traffic congestion in Guangzhou are the general factors: Population $x_{11}$, density of the employed at the end of the year $x_{12}$, density of children in kindergarten $x_{13}$, per capita urban road area $x_{21}$, electric vehicle operating length $x_{31}$, operation of electric vehicle $x_{32}$, rail operation vehicle $x_{34}$, rail passenger traffic volume $x_{35}$, passenger volume and number of trips $x_{37}$, civil trucks owned by every ten thousand people $x_{43}$, occurance times of urban road accidents $x_{51}$, direct property loss caused by urban road accidents $x_{52}$, urban exhaust $x_{61}$, energy consumption of urban transportation $x_{71}$. When the general factors increase by every $1 \%$, the delay cost of traffic congestion in Guangzhou only increases (in the same direction) or decreases (in the opposite direction) by less than $0.5 \%$.

\section{Countermeasures AND Suggestions ON Alleviating Urban Traffic Congestion}

After analyzing the factors that affect the delay cost of traffic congestion, we found that these factors have positive or negative effects on urban traffic congestion to varying degrees. In order to alleviate urban traffic congestion, the following recommendations are put forward:

First, controlling and reducing the population density and the number of passenger cars appropriately. The population density and the number of passenger cars carried by taxi affect the delay cost and the degree of traffic congestion in the same direction. The delay cost of traffic congestion can be reduced and the urban traffic congestion can be alleviated by controlling and reducing the population density and taxi passenger volume.

Second, increasing the number of taxis per 10000 people in a moderate way. The number of taxis owned per 10000 people has a negative impact on the delay cost of traffic congestion and the traffic congestion. By appropriately increasing this number, the delay cost of traffic congestion can be reduced and urban traffic congestion can be alleviated.

Third, urban development and urban industry development plans need to be formulated according to the local conditions. The factors, such as urban scale, urban facilities, urban public transport, urban motor vehicle ownership, urban road accidents, urban exhaust, urban transportation energy consumption, have positive or negative effects on traffic congestion. On the basis of the overall consideration of urban differences, urban development and urban industry development plans should be formulated according to local conditions. By doing this, city traffic congestion delay cost can be reduced, and the urban traffic congestion can be eased.

Fourth, changing the concept of travelling, improve the environment of slow traffic. We should guide the public to choose green way to travel, build and improve the slow transportation system such as walking and cycling. In addition, we should formulate the special planning of urban public bicycle transportation system according to local conditions, and clarify the development orientation, facility network, operation mode and guarantee mechanism of urban public bicycle.

\section{Conclusion}

The research on the delay cost and elasticity of traffic congestion delay cost in Beijing, Shanghai and Guangzhou will surely create greater significance if it is extended to the first-tier, second-tier, third tier and fourth-tier cities in China. Due to the differences in cities, it is imperative to make a further study on the delay cost of urban traffic congestion and the elasticity of delay cost 
of traffic congestion, analyze the influencing factors of urban traffic congestion delay cost, and formulate urban and urban industry development plans according to local conditions. All these measures will be helpful to alleviate urban traffic congestion.

\section{ACKNOWLEDgEMENT}

This paper is supported by the key project of philosophy and social fund of universities in Jiangsu Province (2014ZDIXM038, 2017ZDTXM017，2017ZDIXM046) and the National Natural Science Foundation of China (71874073).

\section{REFERENCES}

1. Ministry of Transport, Outline of Urban Public Transport Development during 13th Five Year Plan, July 20, 2016.

2. CPC Central Committee, the State Council. Outline of Building Transportation Power [EB/OL]. [201909-19]. $\quad \mathrm{http}: / / w w w . g o v . c n / z h e n g c e / 2019$ 09/19/content_5431432.htm

3. Levinson D, D Gillen, A Kanafani et al. The full cost of intercity transportation: a comparison of high speed rail, air and highway transportation in California. Berkeley, CA: University of California at Berkeley, Institute of Transportation Studies, 1996.

4. Maibach M, C Schreyer, D Sutter et al. Hand-book on estimation of external costs in the transport sector internalization measures and policies for all external cost of transport (IMPACT). Delft: CE Delft, 2008.

5. Essen H, A Schroten and M Otten et al. External costs of transport in Europe: update study for 2008. Delft: CE Delft, 2011.

6. Bickel P, R Friedrich. External costs of transport in Germany [J]. Berlin Heidelberg Springer, 1997: 341356.

7. Beuthe M, F Degrandsart, J F Geerts et al. External costs of the Belgian interurban freight traffic: a network analysis of their internalization [J]. Transportation Research Part D Transport \& Environment, 2002, 7(4): 285-301.

8. Blaeij A D, R J G M Florax, P Rietveld et al. The value of statistical life in road safety: a metaanalysis[J]. Accident Analysis \& Prevention, 2003, 35(6): 973-986.

9. Jakob A, J L Craig, G Fisher. Transport cost analysis: a case study of the total costs of private and public transport in Auckland [J]. Environmental Science \& Policy, 2006, (9): 55-66.

10. Quinet E. The Social Costs of Transport: Evaluation and Links with Inernalisation Policies. Energies, 2011.

11. Xie Xuxuan, Zhang Shiqiu, Yi Ru, Wu Dan, Huang Desheng. The Social Cost of Transpor tation Congeston jn Beijing [J]. China opulation, Resources and Environment, 2011,21(1):28 32.
12. Zong Gang, LI Cong. Quantitative Analysis and Calculation of the Negative Externality of Beijing Transportation System[J]. Ecological Economy, 2014,30(5):57 63.

13. Schade W, C Doll, $M$ Maibach et al. Compete $f$ inal report: analysis of the contribution of transport policies to the competitiveness of the EU economy and comparison with the United States. Karlsruhe, Germany: ISI, INFRAS, TIS, Europe Economics, 2006.

14. Cui Zhitao, Huo Yamin. Analyses of Exterior Cost About City Traffic Congestion [J]. Journal of Wuhan University of Technology (Transportation Science \& Engineering), 2006,30(1):147 149.

15. Luo Qingyu, Juan Zhicai, Sun Baofeng, Jia Hongfei. Method Research on Measuring the External Costs of Urban Traffic Congestion [J]. Journal of Transportation Systems Engineering and Information Technology, 2007,7 (5):9 12.

16. Ren Hengkuan. Economic Benefits Evaluation and Analysis of Traffic Congestion on Mental Costs in Urban Area [D]. Beijing Jiaotong University, 2010.

17. Wu Qibing, Chen Feng1, Huang Yao, Hu Yingyue. Calculation and Analysis ofTraffic Congestion Cost in Beijing $[\mathrm{J}]$. Journal of Transportation Systems Engineering and Information Technology, 2011,11(1): $168 \sim 172$.

18. Li Lin. A Study on Our Urban Road Traffic Congestion Cost Estimates and Countermeasures [D]. Dalian Maritime University, 2013.

19. Tong Qing, Wang Jiaqing, Wang Jing. Research on measurement and internalization of external cost of road traffic in Beijing [J]. Management World, 2014, (3): $1 \sim 9,40$.

20. Wang Zhenpo, Zhu Dan, Wang Liyan, Song Shuenfeng. Study on the Group Difference and Decreasing Mechanism of Traffic Congestion Cost of Urban Residents from the Perspective of Time Value: A Case Study in Tianjin [J]. Urban Development Studies, 2017,24,(9):22 28 .

21. Traffic Analysis Report of Major Cities in China in 2016[R]. Beijing: Gaode Map, 2017, (1): 27 28 .

22. Traffic Analysis Report of Major Cities in China in 2017[R]. Beijing: Gaode Map, 2018, (1): 27.

23. Belenky P. Revised departmental guidance on valuation of travel time in economic analysis [R]. Washington DC: U.S. Department of Transportation, 2011.

24. Ren Yiyi. methods of measurement of different costs caused by traffic congestion[D]. Harbin Institute of Technology, 2018.

25. Chenzhen. Selection of Turn-back Stations in Shortturn Routing Mode Based on Passenger Traveling Time Cost and Enterprise Operation Cost [J]. Journal of Transportation Engineering, 2018,18(2):24 28.

26. Xinhua News Agency. Outline of 13th Five Year Plan for National Economic and Social Development 
of People's Republic of China[EB/OL]. [2016-03-17]. http://www.gov.cn/xinwen/201603/17/content 5054992.htm.
27. Quan Yongshen, Wen Huimin, Pan Zhaoyu. Block Control or Block up? Reflection on Current Countermeasures for Urban Traffic Congestion Control[J]. City, 2011, (9):39 43. 